\title{
Article \\ Carbon Nanotori Structures for Thermal Transport Applications on Lubricants
}

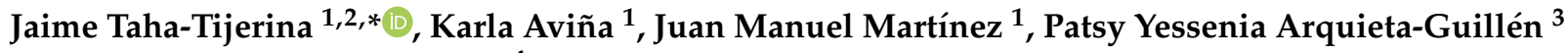 \\ and Marlon González-Escobedo 4
}

1 Departamento de Ingeniería, Universidad de Monterrey, Av. Ignacio Morones Prieto 4500 Pte., San Pedro Garza García 66238, NL, Mexico; karla.avina@udem.edu (K.A.); juan.martineza@udem.edu (J.M.M.)

2 Department of Manufacturing and Industrial Engineering, University of Texas Rio Grande Valley, Brownsville, TX 78520, USA

3 Facultad de Ciencias Físico-Matemáticas, Universidad Autónoma de Nuevo León, San Nicolás de los Garza 66455, NL, Mexico; patsy.arquietagl@uanl.edu.mx

4 Facultad de Ciencias Biológicas, Universidad Autónoma de Nuevo León, San Nicolás de los Garza 66455, NL, Mexico; marlon.gonzalezes@uanl.edu.mx

* Correspondence: jose.taha@udem.edu

Citation: Taha-Tijerina, J.; Aviña, K.; Martínez, J.M.; Arquieta-Guillén, P.Y.; González-Escobedo, M. Carbon Nanotori Structures for Thermal Transport Applications on Lubricants. Nanomaterials 2021, 11, 1158. https:// doi.org/10.3390/nano11051158

Academic Editors: S. M. Sohel

Murshed and Patrice Estellé

Received: 9 March 2021

Accepted: 25 April 2021

Published: 29 April 2021

Publisher's Note: MDPI stays neutral with regard to jurisdictional claims in published maps and institutional affiliations.

Copyright: (c) 2021 by the authors. Licensee MDPI, Basel, Switzerland. This article is an open access article distributed under the terms and conditions of the Creative Commons Attribution (CC BY) license (https:// creativecommons.org/licenses/by/ $4.0 /)$.

\begin{abstract}
Carbon nanostructures have been recently applied to improve industrial manufacturing processes and other materials; such is the case for lubricants used in the metal-mechanic industry. Nanotori are toroidal carbon nanostructures, obtained from chemical treatment of multi-wall carbon nanotubes (MWCNTs). This material has been shown to have superb anti-wear and friction reduction performance, having the ability to homogeneously disperse within water in concentrations between 1-2 wt.\%. Obtained results of these novel nanostructures under water mixtures and novel additives were a set point to our studies in different industrial lubricants. In the present work, nanotori structures have been applied in various filler fractions as reinforcement to evaluate the behavior in thermal transport of water-based (WB) and oil-based (OB) lubricants. Temperature-dependent experiments to evaluate the thermal conductivity were performed using a thermal water bath ranging from room temperature up to $323 \mathrm{~K}$. The obtained results showed a highly effective and favorable improvement in the heat transport of both lubricants; oil-based results were better than water-based results, with nanotori structures increasing the lubricants' thermal transport properties by $70 \%$, compared to pure lubricant.
\end{abstract}

Keywords: thermal conductivity; nanotori; lubricants; water-based; oil-based

\section{Introduction}

In industrial manufacturing systems a remarkable search to obtain the suitable material application and performance, optimizing devices, machines and designs, maintain or reducing materials consumption and pollution mitigation. Thermal transport plays a vital role in industrial manufacturing systems and due to global market competition and cost reduction endeavors, design miniaturization has required improvements in the thermal performance (heat dissipation efficiency) of lubricants and fluids [1].

Lubricants and fluids are required in numerous engineering applications and fields such as energy, transportation, defense, aerospace, microelectronics, power transmission, and nuclear systems cooling, among others [2-4], for thermal transport and reduction of wear and friction in metal-mechanic manufacturing operations, such as in formingpunching, machining, drilling, among others [5]. These materials provide a proper working component interface, removing chips and debris from machined surfaces, reducing the risks associated with machinery failure or tooling damage, improving the quality of working components. 
Early investigations used millimeter or micrometer-sized particle suspensions in order to improve material performance. Nevertheless, initially, this led to a range of issues such as a rapid sedimentation tendency of these solid structures within the fluidic media; forming sludge sediments; limiting the thermal transport capacity; and increasing the thermal resistance of the conventional fluids and lubricants.

With the aid of nanotechnology, diverse heat transfer fluidic media have been investigated in order to improve thermal transport behavior, characteristics and performance [6-13]. Nanofluids, and some nanolubricants, are highly effective thermal transport media as a result of their anomalous high thermal characteristics. Solid nanostructures possess high thermal conductivity, measuring several orders of magnitude higher than conventional heat transfer lubricants, fluids, and mixtures of both. Integration of reinforcing nanostructures within conventional materials results in higher thermal conductive mixtures that could enhance performance and efficiency in diverse systems [14]. Among the benefits of nanofluids and nanolubricants, one of the attractive characteristics is that these materials can be optimally engineered to achieve particular objectives, such as anti-wear properties, thermal energy storage capacity, high thermal conductivity, better temperature stabilization and lower pressure drop [15]. Nevertheless, even though nanofluids and nanolubricants are promising for many practical applications, care must be taken to maintain the integrity of the systems and eliminate undesirable properties. Potential drawbacks of adding nanoreinforcements to conventional materials pertain to viscosity, nanostructures' agglomeration, and sedimentation, among others [15-17].

A carbon nanotube (CNT) is a carbon-based material in tubular shape, a few nanometers in diameter. Carbon-based nanostructures can be produced in a variety of sizes and lengths. They resemble black powder on a macro scale. Among a wide range of nanostructures, varying from low to very high thermal conductivity, carbon-based materials have been shown to provide the highest thermal conductivity improvements compared to other particle types. Experiments have been conducted on carbon-based nanostructures such as graphene, carbon fibers, and CNTs, in order to increase thermal transport performance of conventional materials [18-25]. In diverse studies, nanomaterials developed with allotropes of carbon (graphene, diamond, CNTs, carbon fibers, etc.) and oxide-based materials generally contain more than $1.0 \mathrm{wt}$ \% of these reinforcements' concentration [9,26-29]. Nanofiller concentrations up to up to 10-12 wt.\% have been incorporated into conventional media to enhance the system's thermal characteristics (typically by at least $12 \%$ in thermal conductivity). However, such concentrations of nanostructures showed various negative effects, such as an increase in the suspension's viscosity, as well as cost. The higher concentrations of nanofillers adversely affect the material fluidity, threaten the nanofluid 's stability, and thermal management goals.

Choi et al. [30] reported superb thermal conductivity improvements for multi-wall CNTs (MWCNTs) reinforcing synthetic poly ( $\alpha$-olefin) oil (PAO). They achieved enhancement of $160 \%$ at 1.0 vol. \% of MWCNTs. The effects of solid nanostructures at various volume fractions and temperatures on thermal transport performance of hybrid CNTs$\mathrm{Al}_{2} \mathrm{O}_{3}$ /water nanofluids was investigated by Esfe et al. [31], they found that thermal conductivity improvement was due to the high number of solid reinforcements and rise in evaluating temperatures. Farbod et al. [32] prepared water-based nanofluids at various concentrations and lengths of functionalized MWCNTs. An improvement in thermal conductivity was observed with increasing the temperature and with decreasing the length of the MWCNTs, suggesting a percolation channel formation and interlayer interactions between the carbon nanostructures and the media. A study performed by Ilyas et al. [33] on commercial brand oil with MWCNTs reinforcements, showed a significant thermal conductivity enhancement at $1.0 \mathrm{wt}$. \% of 22 and $33 \%$ at 35 and $333 \mathrm{~K}$, respectively. Naddaf et al. [23] observed significant enhancements in thermal conductivity $(>80 \%$, when compared to pure diesel oil) with the increase in temperature, up to $373 \mathrm{~K}$, for graphene nanoplatelets- and MWCNT/diesel oil nanofluids. Similarly, Shanbedi et al. [34] observed that increasing the filler fraction and temperature of their studied water-based nanofluids, an improvement 
in the effective thermal conductivity performance was achieved. Graphene nanoplatelets were dispersed within water and ethylene glycol (EG) by Selvam et al. [35]. It was observed that as the filler fraction of graphene nanoplatelets was increased, the thermal conductivity ratio was enhanced. Particularly, an improvement of $20 \%$ and $15 \%$, for EG and water media was observed at 0.5 vol.\%, respectively. On other carbon structures, Branson et al. investigated nanodiamonds (NDs) dispersed within EG and mineral oil (MO) [26]. In their studies, incorporation of $0.88 \mathrm{vol} . \%$ of NDs increased the thermal conductivity by $\sim 12 \%$. Moreover, $6 \%$ and $11 \%$ increases were achieved at 1.0 and 1.9 vol. $\%$, respectively. Similarly, Yu et al. [36] showed that incorporation of small concentrations ( $1.0 \mathrm{vol} \%)$ of NDs to EG produced thermal conductivity enhancements of around $17 \%$. In previous work by Taha-Tijerina et al. [8], even less filler fraction of NDs ( $0.1 \mathrm{wt} . \%)$ was homogeneously dispersed within MO-based nanofluids with significant improvements of $\sim 70 \%$.

Among these carbon-based materials, less-common structures have been recently studied for mechanical applications and other functions. These novel material configurations are called nanotori or nanorings, comprising of circular CNTs formed by connecting their two ends. The toroidal-like structures are closely related to the well-known sphere-like nanostructures. As mentioned by Kharissova et al. [37], these torus-like materials have been studied more theoretically than experimentally. However, scientific studies have shown their superb properties and promising applications. Recently, carbon nanotori structures have been evaluated as reinforcements for conventional lubricants and fluids in the metal-mechanic field, allowing a reduction in wear and friction [38].

Due to their exceptional characteristics and similarity to CNTs, carbon nanotori structures are proposed as reinforcing material for metal-forming lubricants. In this research, water-based (WB) and oil-based (OB) nanolubricants consisting of varying carbon nanotori filler fractions (by weight) aim to determine their thermal transport performance (thermal conductivity) over a range of temperatures (up to $323 \mathrm{~K}$ ).

\section{Materials and Methods}

\subsection{Preparation of Nanolubricants}

In our research, two commonly applied lubricants (FUCHS Industry), water-based and oil-based, for metal-forming applications; punching, stamping, and drawing, among others, are used as conventional materials (see Table 1). Their general characteristics provide a light but effective film to dissipate heat and reduce wear in tools and machinery. These materials were reinforced with carbon nanotori at various filler fractions: $0.01 \mathrm{wt} . \%$, $0.05 \mathrm{wt} . \%$ and $0.10 \mathrm{wt} . \%$. Multi-walled carbon nanotubes (MWCNTs) $(30-50 \mathrm{~nm}$ in diameter) functionalized with carboxylic acid $(\mathrm{COOH})$ groups were dissolved in an acid solution of nitric acid $\left(\mathrm{HNO}_{3}\right)$, sulfuric acid $\left(\mathrm{H}_{2} \mathrm{SO}_{4}\right)$, hydrochloric acid $(\mathrm{HCl})$, potassium permanganate $\left(\mathrm{KMnO}_{4}\right)$, hydrogen peroxide $\left(\mathrm{H}_{2} \mathrm{O}_{2}\right)$, and deionized water (DiW) [39]. Afterwards, magnetic stirring was performed to the solution in a glass container in an ice bath for $48 \mathrm{~h}$. Then, the solution was moved to a glass container where DiW was poured at $20 \%$ concentration and maintained for another $24 \mathrm{~h}$ (Figure 1a). $\mathrm{HCl}$ and $\mathrm{H}_{2} \mathrm{O}_{2}$ were used to clean the solution which is centrifuged afterwards to obtain the supernatant which contains the carbon nanotori. Figure $1 \mathrm{~b}$ shows a TEM (Hitachi H-9500, Tokyo, Japan, electron microscope operated at $300 \mathrm{keV}$ ) image of carbon nanotorus suspended in DiW; these nanostructures have a torus diameter of $\sim 130 \mathrm{~nm}$, and tube diameter of $\sim 40 \mathrm{~nm}$. Dynamic light scattering (DLS) (Malvern Zetasizer Nano ZS, Almelo, The Netherlands) was used to determine that the average outer diameter of these nanostructures was $\sim 177 \mathrm{~nm}$ with a polydispersity index of 0.248 and zeta potential of $-26.5 \mathrm{mV}$ [38].

Raman spectroscopy for nanotori structures (Raman: Micro-RAMAN DXR Thermoscientific, Sussex, UK at $532 \mathrm{~nm}$ ) is shown in Figure 2. Synthesis was carried out using MWCNTs, whose characteristic Raman spectra contain the G band at $1590 \mathrm{~cm}^{-1}$, (the same spectra of almost all carbon nano forms); the D band around at $1320 \mathrm{~cm}^{-1}$ indicates a structural defect of graphene; and the band at $2700 \mathrm{~cm}^{-1} \mathrm{G}^{\prime}$ (also known as 2D) is used to get information about the electronic and geometrical structure. These spectra allow 
us to confirm that nanotori structures are conformed from MWCNTs in toroidal shape. Additionally, the increment at $1600 \mathrm{~cm}^{-1}$ allows us to know that changes exist in the geometric structure. This increment in Raman absorption reflects a change in crystallinity of the material.

Table 1. Material characteristics.

\begin{tabular}{cccc}
\hline Materials & \multicolumn{3}{c}{ Properties } \\
\hline Base lubricant & Density $(288 \mathrm{~K})$ & $\begin{array}{c}\text { Kinetic Viscosity } \\
\left(\mathrm{mm}^{2} / \mathrm{s}\right)\end{array}$ & Waer:Oil Ratio \\
\hline \multirow{2}{*}{ Water-based } & $1.031 \mathrm{~g} / \mathrm{cm}^{3}$ & $\begin{array}{c}2.02 @ 298 \mathrm{~K} \\
0.86 @ 343 \mathrm{~K}\end{array}$ & $6: 1$ \\
\hline \multirow{2}{*}{ Oil-based } & $0.994 \mathrm{~g} / \mathrm{cm}^{3}$ & $\begin{array}{c}63.3 @ 298 \mathrm{~K} \\
40.7 @ 343 \mathrm{~K}\end{array}$ & $4: 1$ \\
\hline Nanoparticles & Size $/$ Geometry & Polydispersity Index & Zeta Potential \\
\hline Carbon & Tube diameter $\sim 40 \mathrm{~nm}$ & 0.248 & $-26.5 \mathrm{mV}$ \\
nanotori & Torus diameter $\sim 130 \mathrm{~nm}$ & & \\
\cline { 2 - 4 } & OD $177 \mathrm{~nm}$ & & \\
\hline
\end{tabular}

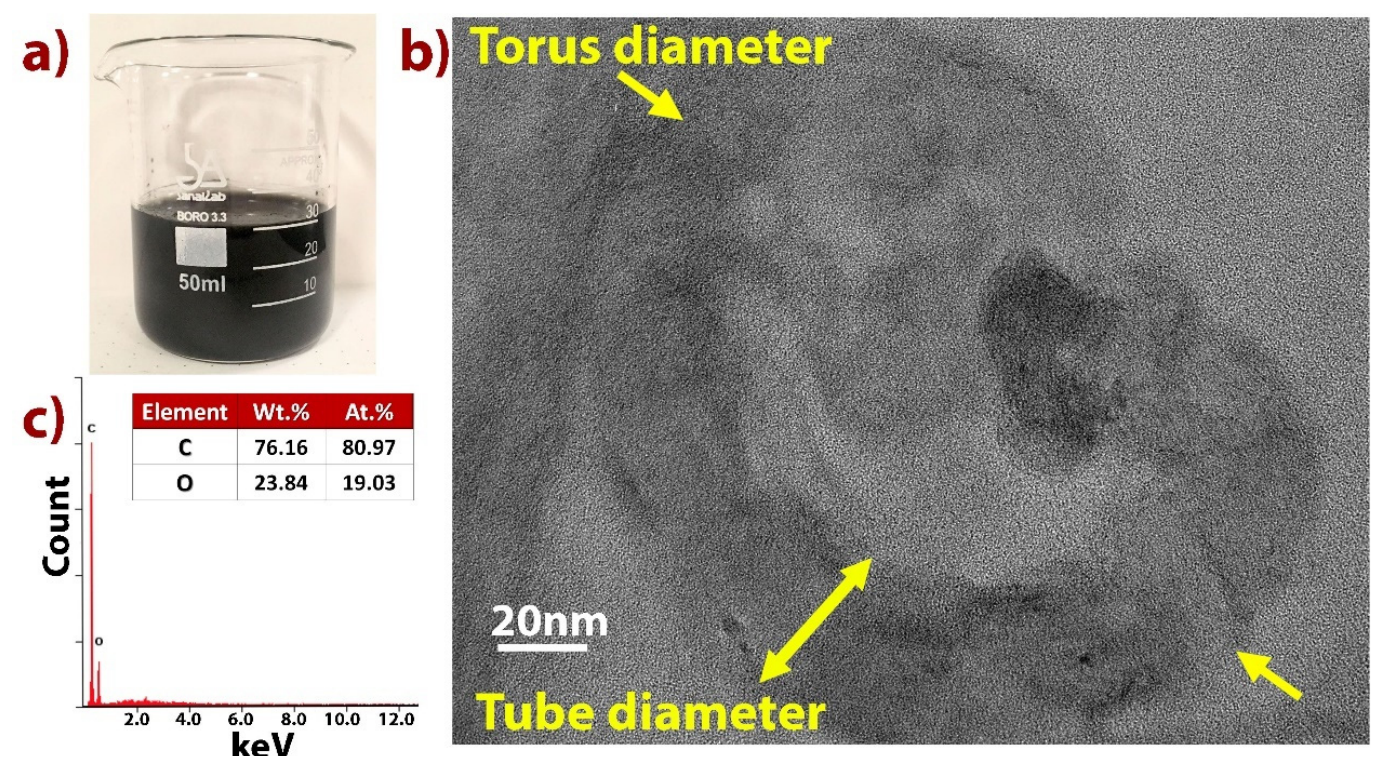

Figure 1. (a) Carbon nanotori structures suspended within DiW; (b) TEM of analyzed carbon nanotori; and (c) EDAX analysis of carbon nanotori. 


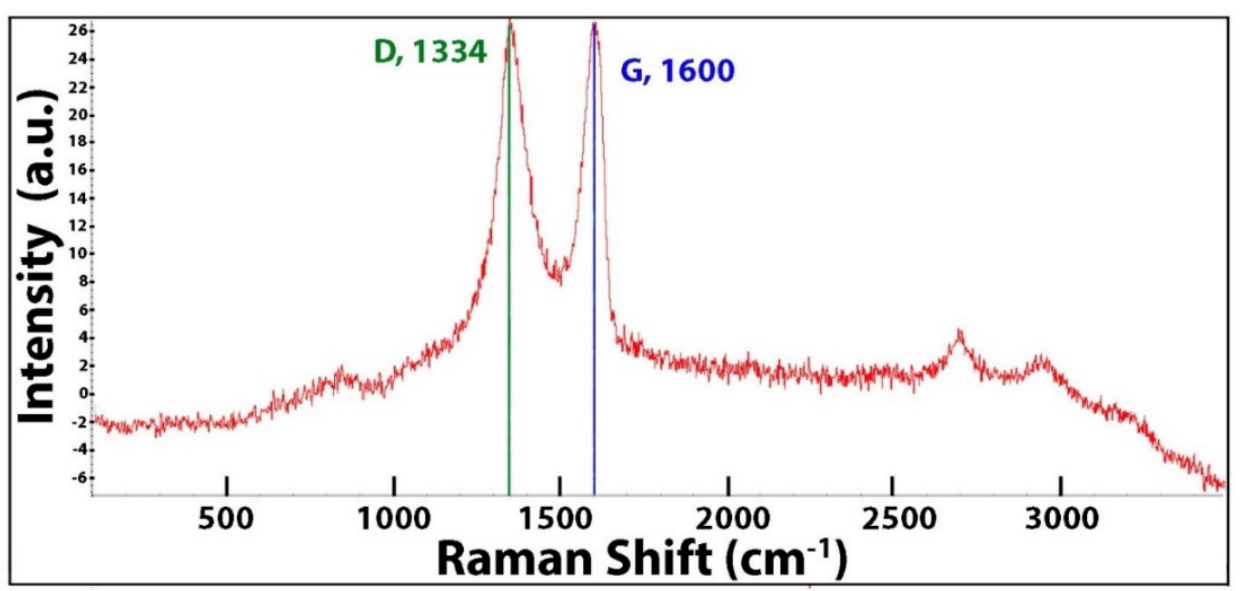

Figure 2. Raman spectrum for carbon nanotori structures.

Once carbon nanotori structures were obtained, they were dispersed within WB and OB lubricants. Then, $40 \mathrm{~mL}$ glass vials were prepared at various filler fractions: $0.01 \mathrm{wt} . \%$, $0.05 \mathrm{wt} . \%$ and $0.10 \mathrm{wt}$.\% of nanotori. To homogeneously disperse the nanostructures, an ultrasonic dismembrator was used (Branson ultrasonic homogenizer model 5510-40 kHz) for a prolonged time (5-6 h). To prevent any agglomeration and fast sedimentation of nanostructures, the sonicator bath water temperature was maintained constant at room temperature $(297 \mathrm{~K})$, and the bath water was changed every hour. Vials were kept on a shelf for at least 4 weeks without significant visible settling or sedimentation. UV-Vis spectra of carbon nanotori WB lubricant at $0.10 \mathrm{wt}$ \% $\%$ is shown in Figure 3. Overlap of as prepared $(0 \mathrm{~h})$ sample (black) and sample after 10 weeks are presented with no significant structural changes, confirming what we observed regarding the stability of the suspensions after a long shelf-sitting time.

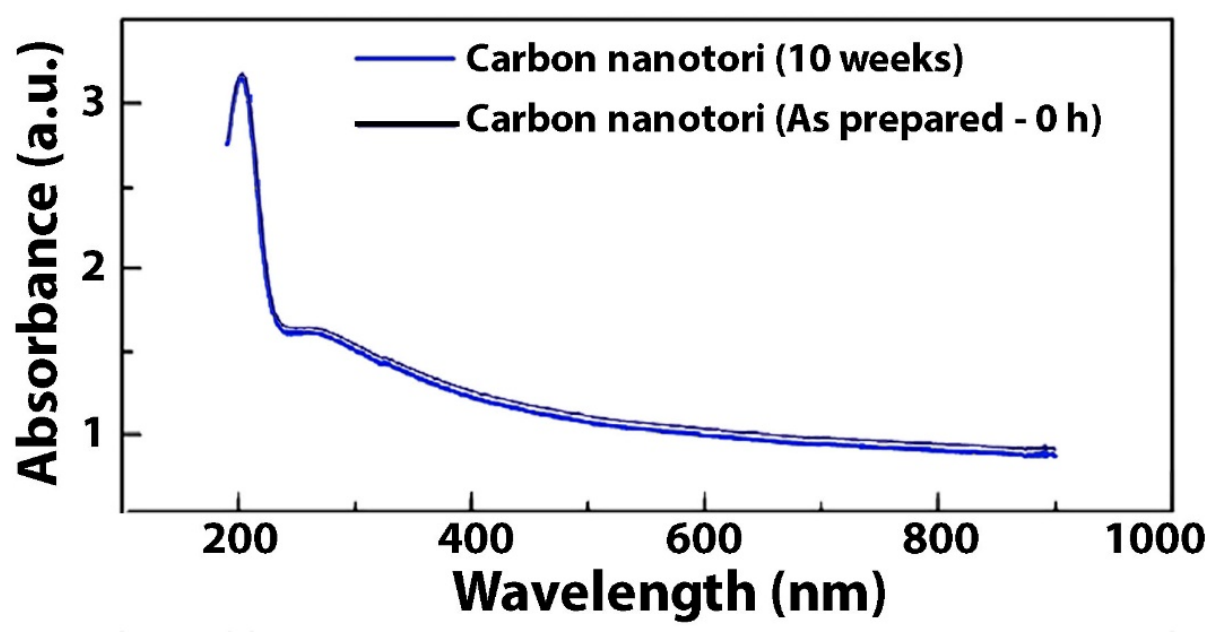

Figure 3. UV-Vis spectra of carbon nanotori WB lubricant at $0.10 \mathrm{wt} . \%$.

\subsection{Thermal Conductivity Measurements}

There are diverse methodologies and techniques to determine and evaluate the thermal conductivity of fluidic media: transient hot-wire technique $[14,40,41]$, cylindrical cell method [42], steady-state method [43,44], temperature oscillation method [45], and 3- $\omega$ method $[46,47]$. In our research, thermal evaluation was performed by thermal conductivity measurements of conventional WB and OB nanolubricants at various carbon nanotori filler fractions according to the transient hot-wire (THW) methodology, with a KD2 Pro instrument (Decagon, Inc., Pullman, WA, USA). This technique obtains the thermal conductivity of a fluidic media which is determined based on measuring the time response and 
temperature of a metal probe subjected to an immediate electrical pulse, which functions both as a heater and temperature sensor. The KD2 Pro works with stainless-steel probe (KS-1; $1.3 \mathrm{~mm}$ in diameter by $60 \mathrm{~mm}$ long) which is fully immersed in the vial sample to obtain the effective thermal conductivity of nanolubricants. The probe temperature is slowly increased by providing a constant current through resistive heating; the heat is dissipated from the sensor to the surrounding media through conduction, hence, increasing its temperature. This temperature rise depends on the media's thermal conductivity. Finally, the thermal conductivity value is obtained from the heating power and the slope of the temperature change through the device algorithm using a logarithmic time scale. The transient hot-wire method has the advantages of fast measurements and low cost, which increases the ease of implementation. The system was calibrated/verified before the measurements were taken, using a standard fluid (glycerol) and corroborated data for DiW and EG. The thermal conductivity values are verified up to 3 decimal points. Enhancements in thermal conductivity were obtained, considering the ratio of effective thermal conductivity of the nanofluids $\left(k_{\text {eff }}\right)$ and pure lubricants, WB and OB lubricants, respectively, $\left(k_{0}\right)$ and $\left(\left(k_{e f f} / k_{0}\right)-1\right) \%$.

Temperature-dependent measurements were performed using a water bath ranging at various temperatures from room temperature ( $297 \mathrm{~K}$ ) up to $323 \mathrm{~K}$ (See Figure 4 ). Each sample was thermally equilibrated before each measurement for 10-15 min. Average thermal conductivity values were taken with standard deviation from at least 6 measurements from each set of nanolubricants.

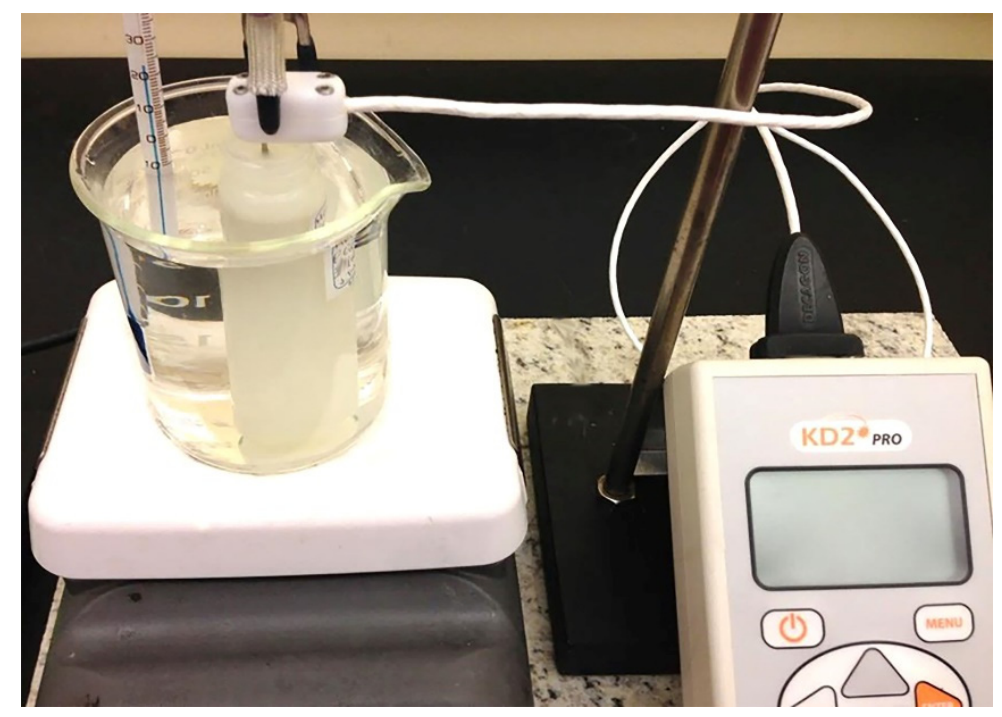

Figure 4. Illustration of configuration used for thermal evaluation for nanolubricants.

\section{Results}

Improvements in thermal conductivity for carbon nanotori within $\mathrm{OB}$ and WB lubricant systems have been obtained. Figure 5 shows the temperature-dependent thermal conductivity performance of these systems at various carbon nanotori filler fractions; error bars depict the standard deviations.

Pure WB lubricant did not show considerable temperature dependency (less than 2\% at $323 \mathrm{~K})$. All WB nanolubricants showed gradually thermal conductivity increments as carbon nanotori concentrations and temperature were also increased, indicating the thermal behavior of carbon-based nanostructures. Moreover, the incorporation of carbon nanotori produced important thermal conductivity enhancements as evaluating temperature was increased. For instance, at $323 \mathrm{~K}, \mathrm{WB}$ nanofluids achieved enhancements of 24,33 and a maximum of $46 \%$ at $0.01 \mathrm{wt} . \%, 0.05 \mathrm{wt} . \%$ and $0.10 \mathrm{wt} . \%$, respectively, when compared to pure WB lubricant. 
Similar to WB lubricants, OB lubricants did not show temperature dependency (less than $2 \%$ at $323 \mathrm{~K}$ ). Thermal conductivity evaluations were performed as filler fractions and temperatures were increased, to determine their temperature-dependency behavior. The incorporation of carbon nanotori reflected significant improvements as temperature was increased. At $313 \mathrm{~K}$ for instance, OB nanofluids achieved enhancements of $16 \%, 24 \%$ and $36 \%$, at $0.01 \mathrm{wt} . \%, 0.05 \mathrm{wt} . \%$ and $0.10 \mathrm{wt} . \%$, respectively. Superb behavior observed was achieved at $323 \mathrm{~K}$, with maximum enhancement of $70 \%$ at $0.10 \mathrm{wt} . \%$.

Incorporation of carbon nanotori, even at very low filler fractions (up to $0.10 \mathrm{wt} . \%$ ), significantly enhances the thermal conductivity performance of nanolubricants, which is mainly attributed to the inherent high heat transfer capacity of carbon-based nanostructures.
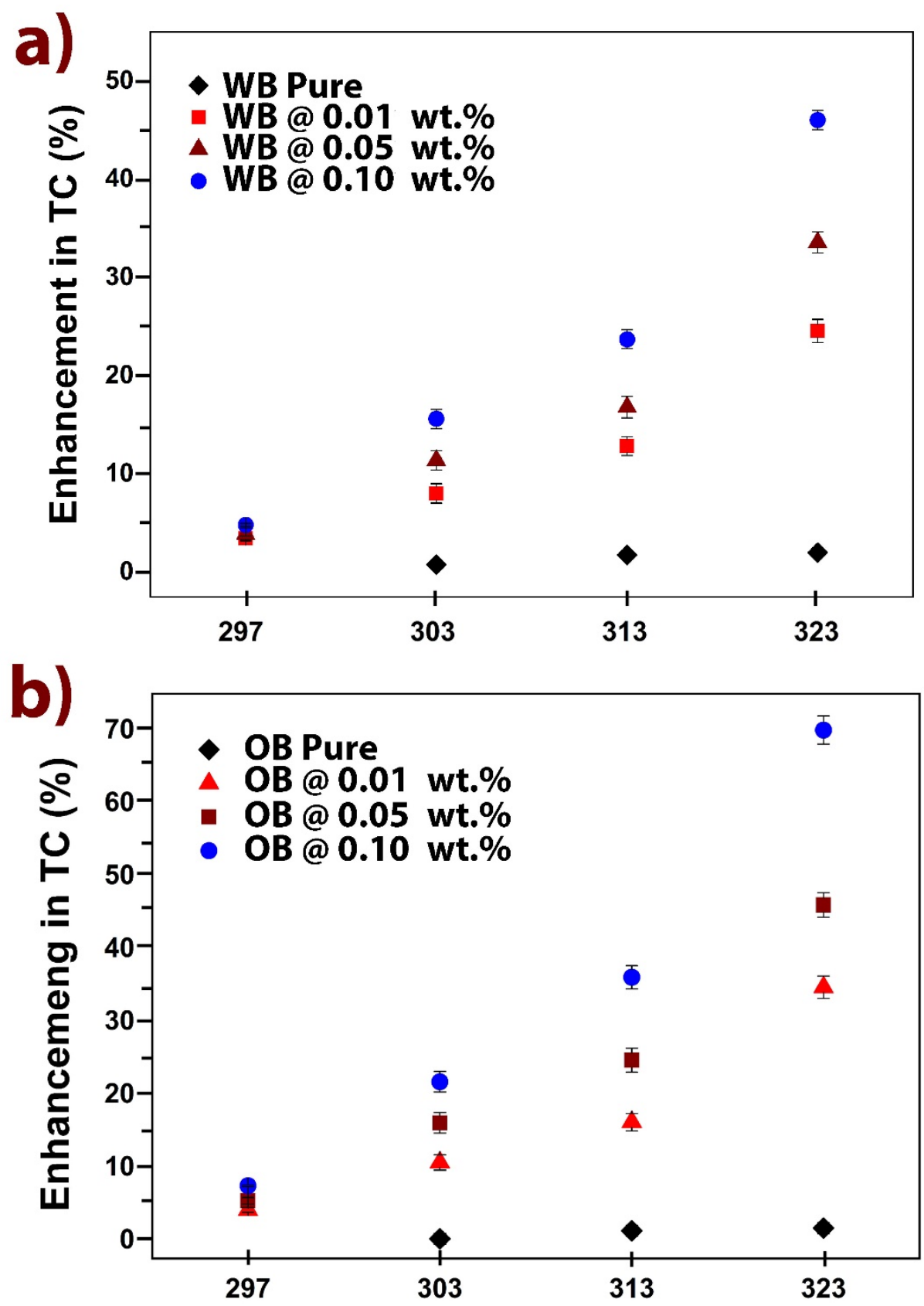

Figure 5. Thermal conductivity enhancements under temperature-dependence evaluation. (a) waterbased lubricants; (b) oil-based lubricants (percentage of filler amount is mentioned).

Due to the low applied nanostructures concentrations, the resulting improvements in thermal conductivity could be attributed to diverse factors, such as molecular inter- 
actions between the lubricants and carbon nanostructures $[18,22,25,48]$, and percolation mechanism [49-51]. As the nanotori filler fraction is increased within the lubricants, the nanostructures' distance is decreased, thus increasing the contact probability among them; therefore, thermal transport channels are formed, increasing the thermal conductivity behavior due to the percolation mechanism [52]. Another important factor is the Brownian motion contribution of the carbon nanostructures [51-54]. For instance, an increase in the thermal conductivity of the nanolubricants can be induced by the heat transport between colliding nanostructures, particularly at higher temperatures, corresponding to more intense Brownian motion [55-57]. Furthermore, liquid layering at the lubricant/nanotori interface could also contribute to the increased behavior of thermal conductivity [58-60]. Effective thermal conductivities $\left(k_{e f f}\right)$ of nanolubricants increase with temperature (room temperature up to $323 \mathrm{~K}$ ), indicating the role of Brownian motion on measured thermal conductivities, in accordance with Maxwell's predictions [61,62].

Theoretical approaches and correlations used to describe and explain improvements in thermal transport performance for nanomaterials is so complex that the use of a single model is not sufficient to predict the wide range of experimental data [63]. Theoretical models have been used to predict thermal conductivity of nanofluids assuming diverse variables, such as the reinforced nanostructures properties and characteristics being welldispersed within conventional media.

The filler fractions and conductivities of the lubricants will determine the lower and upper boundary values of nanolubricants' effective thermal conductivity $\left(k_{\text {eff }}\right)$. A theoretical model of the $k_{\text {eff }}$ of the nanolubricants is performed using a classical effective medium theory known as Hashin-Shtrikman (H-S) theory [64]. In this case the ratio of $k_{n t} / k_{L}$ is $>1$, where $k_{n t}$ is the thermal conductivity of the carbon nanotori and $k_{L}$ is the thermal conductivity of the lubricants. The lower boundary value (since the nanofillers fraction, $\varphi$, is very low, $0.10 \mathrm{wt} . \%$ ) for effective thermal conductivity of nanolubricants, $k_{\text {eff, }}$, is calculated using the following equation:

$$
\frac{k_{e f f}}{k_{L}}=1+\frac{3 \varphi\left(\frac{k_{n t}}{k_{L}}-1\right)}{\frac{k_{n t}}{k_{L}}+2-\varphi\left(\frac{k_{n t}}{k_{L}}-1\right)}
$$

The calculated value $0.5486 \mathrm{~W} / \mathrm{m} \mathrm{K}$ matches well with the experimental value obtained at room temperature for $0.10 \mathrm{wt} . \%$ nanolubricant $(0.547 \mathrm{~W} / \mathrm{m} \mathrm{K})$. The model from Hashin-Shtrikman (H-S) requires input of the reinforcing nanostructures' thermal conductivity. Carbon nanotori allotropy has not been fully described in literature for its thermal performance. However, carbon nanostructures (graphite, graphene, SWCNTs, MWCNTs) have been reported at various thermal conductivities, varying from 2000 up to $6000 \mathrm{~W} / \mathrm{mK}$ [65-69]. For our evaluations, we selected a lower value considering the structural configuration (ring/tori) of the nanostructure in our research. In this case, carbon nanotori structures were considered to have a thermal conductivity of $2200 \mathrm{~W} / \mathrm{mK}$, which was applied as $k_{n t}$ value.

From a theoretical point of view, with the increase of the nanofluid's bulk temperature, molecules and nanostructures are more active and able to transfer more energy from one location to another per unit time. The temperature-dependent variations in thermal conductivity indicate that it is not just the percolation mechanism that increases the thermal conductivity, but also Brownian motion contributes to the thermal transport behavior of carbon nanotori-based nanolubricants as well.

\section{Conclusions}

Reinforcing conventional materials with solid carbon nanotori structures, promotes highly effective heat transfer behavior, which is mainly attributed to its anomalous high thermal conductivity at very low concentrations up to $0.10 \mathrm{wt} . \%$. Two conventional metalforming lubricants were analyzed, water-based and oil-based. For oil-based lubricants, thermal conductivity improvements were observed as carbon nanotori and evaluating 
temperatures were increased, reaching a maximum of $46 \%$ at $323 \mathrm{~K}$ with merely $0.10 \mathrm{wt}$. $\%$. The greatest impact was shown with oil-based lubricants, probably due to the oleophilic compatibility of carbon nanostructures. Here, the enhancement was observed to achieve $36 \%$ at $313 \mathrm{~K}$. The maximum improvement was shown at $323 \mathrm{~K}$ up to $70 \%$ for $0.10 \mathrm{wt}$. $\%$ filler fraction of carbon nanotori. Carbon nanostructures are shown to have good compatibility with conventional lubricants and may significantly improve thermal conductivity when used as reinforcements. Considering the suitability of the reported carbon-reinforced nanolubricants for thermal industrial manufacturing processes, the need of predictive methodologies for thermal transport is an area of opportunity for further development and study.

Author Contributions: J.T.-T. contributed to the conceptualization, methodology, measuring campaign, literature research, project administration, data interpretation, data analysis, validation, formal analysis, resources, investigation, figures, study design, supervision and writing-original. P.Y.A.-G. contributed to the methodology, measuring campaign, resources, data interpretation, validation, formal analysis, investigation, figures, and writing-original. K.A. and J.M.M. contributed to the methodology, measuring campaign, data interpretation and investigation. M.G.-E. contributed to the investigation and formal analysis. All authors have read and agreed to the published version of the manuscript.

Funding: This research received no external funding.

Data Availability Statement: The data obtained and utilized in this research has been shown in the figures and graphics, that is all we have to share.

Acknowledgments: Authors acknowledge Metalsa and Universidad de Monterrey for their support given in this research.

Conflicts of Interest: The authors declare no conflict of interest.

\section{References}

1. Taha-Tijerina, J.; Aviña, K.; Diabb, J.M. Tribological and thermal transport performance of $\mathrm{SiO}_{2}$-based natural lubricants. Lubricants 2019, 7, 71. [CrossRef]

2. Contreras, J.E.; Rodriguez, E.A.; Taha-Tijerina, J. Nanotechnology applications for electrical transformers-A review. Electr. Power Syst. Res. 2017, 143, 573-584. [CrossRef]

3. Contreras, J.E.; Rodriguez, E.A.; Taha-Tijerina, J. Recent Trends of Nanomaterials for High-Voltage Applications. In Handbook of Nanomaterials for Industrial Applications; Elsevier: Amsterdam, The Netherlands, 2018; pp. 724-738.

4. Taha-Tijerina, J. Thermal transport and Challenges on Nanofluids Performance. In Microfluidics and Nanofluidics; Hussain, C.M., Ed.; Elsevier: Amsterdam, The Netherlands, 2018; pp. 215-256.

5. Xavior, M.A.; Adithan, M. Determining the influence of cutting fluids on tool wear and surface roughness during turning of AISI 304 austenitic stainless steel. J. Mater. Process. Technol. 2009, 209, 900-909. [CrossRef]

6. Azmi, W.H.; Sharma, K.V.; Mamat, R.; Najafi, G.; Mohamad, M.S. The enhancement of effective thermal conductivity and effective dynamic viscosity of nanofluids-A review. Renew. Sustain. Energy Rev. 2016, 53, 1046-1058. [CrossRef]

7. Haghighi, E.B.; Utomo, A.T.; Ghanbarpour, M.; Zavareh, A.I.T.; Nowak, E.; Khodabandeh, R.; Pacek, A.W.; Palm, B. Combined effect of physical properties and convective heat transfer coefficient of nanofluids on their cooling efficiency. Int. Commun. Heat Mass Transf. 2015, 68, 32-42. [CrossRef]

8. Taha-Tijerina, J.J.; Narayanan, T.N.; Tiwary, C.S.; Lozano, K.; Chipara, M.; Ajayan, P.M. Nanodiamond-Based Thermal Fluids. ACS Appl. Mater. Interfaces 2014, 6, 4778-4785. [CrossRef] [PubMed]

9. Sarviya, R.M.; Fuskele, V. Review on Thermal Conductivity of Nanofluids. Mater. Today Proc. 2017, 4, 4022-4031. [CrossRef]

10. Bhogare, R.; Kothawale, B. A Review on applications and challenges of Nano-fluids as coolant in Automobile Radiator. IJSRP 2013, 3, 1-11.

11. Leong, K.Y.; Ku Ahmad, K.Z.; Ong, H.C.; Ghazali, M.J.; Baharum, A. Synthesis and thermal conductivity characteristic of hybrid nanofluids-A review. Renew. Sustain. Energy Rev. 2017, 75, 868-878. [CrossRef]

12. Salehirad, M.; Nikje, M.M.A. Properties of Modified Hexagonal Boron Nitride as Stable Nanofluids for Thermal Management Applications. Russ. J. Appl. Chem. 2019, 92, 78-86. [CrossRef]

13. Wong, K.V.; De Leon, O. Applications of Nanofluids: Current and Future. Adv. Mech. Eng. 2010, 2, 519659. [CrossRef]

14. Taha-Tijerina, J.; Narayanan, T.N.; Gao, G.; Rohde, M.; Tsentalovich, D.A.; Pasquali, M.; Ajayan, P.M. Electrically insulating thermal nano-oils using 2D fillers. ACS Nano 2012, 6, 1214-1220. [CrossRef] [PubMed] 
15. Taha-Tijerina, J.; Peña-Paras, L.; Narayanan, T.N.; Garza, L.; Lapray, C.; Gonzalez, J.; Palacios, E.; Molina, D.; García, A.; Maldonado, D.; et al. Multifunctional nanofluids with 2D nanosheets for thermal and tribological management. Wear 2013, 302, 1241-1248. [CrossRef]

16. Taha-Tijerina, J.; Sakhavand, N.; Kochandra, R.; Ajayan Pulickel, M.; Shahsavari, R. Theoretical Prediction of Physical Properties (Viscosity) on 2D-based Nanofluids. Ing. Investig. Tecnol. 2017, 18, 101-109.

17. Narayanan, T.N.; Gupta, B.K.; Vithayathil, S.A.; Aburto, R.R.; Mani, S.A.; Taha-Tijerina, J.; Xie, B.; Kaipparettu, B.A.; Torti, S.V.; Ajayan, P.M. Hybrid 2D nanomaterials as dual-mode contrast agents in cellular imaging. Adv. Mater. 2012, 24, $2992-2998$. [CrossRef]

18. Borode, A.O.; Ahmed, N.A.; Olubambi, P.A. A review of heat transfer application of carbon-based nanofluid in heat exchangers. Nano Struct. Nano Objects 2019, 20, 100394. [CrossRef]

19. Park, S.; Shon, M. Effects of multi-walled carbon nano tubes on corrosion protection of zinc rich epoxy resin coating. J. Ind. Eng. Chem. 2015, 21, 1258-1264. [CrossRef]

20. Goyal, M.; Sharma, K. Investigation on forced convective heat transfer characteristics of carbon nanomaterial based nanofluids Mater. Today Proc. 2020, 37, 3019-3023. [CrossRef]

21. Li, X.; Chen, W.; Zou, C. The stability, viscosity and thermal conductivity of carbon nanotubes nanofluids with high particle concentration: A surface modification approach. Powder Technol. 2020, 361, 957-967. [CrossRef]

22. Moghaddari, M.; Yousefi, F.; Aparicio, S.; Hosseini, S.M. Thermal conductivity and structuring of multiwalled carbon nanotubes based nanofluids. J. Mol. Liq. 2020, 307, 112977. [CrossRef]

23. Naddaf, A.; Zeinali Heris, S. Experimental study on thermal conductivity and electrical conductivity of diesel oil-based nanofluids of graphene nanoplatelets and carbon nanotubes. Int. Commun. Heat Mass Transf. 2018, 95, 116-122. [CrossRef]

24. Rehman, W.U.; Merican, Z.M.A.; Bhat, A.H.; Hoe, B.G.; Sulaimon, A.A.; Akbarzadeh, O.; Khan, M.S.; Mukhtar, A.; Saqib, S.; Hameed, A.; et al. Synthesis, characterization, stability and thermal conductivity of multi-walled carbon nanotubes (MWCNTs) and eco-friendly jatropha seed oil based nanofluid: An experimental investigation and modeling approach. J. Mol. Liq. 2019, 293, 111534. [CrossRef]

25. Taherian, H.; Alvarado, J.L.; Languri, E.M. Enhanced thermophysical properties of multiwalled carbon nanotubes based nanofluids. Part 1: Critical review. Renew. Sustain. Energy Rev. 2018, 82, 4326-4336. [CrossRef]

26. Branson, B.T.; Beauchamp, P.S.; Beam, J.C.; Lukehart, C.M.; Davidson, J.L.; Science, I.M.; Engineering, M.; Engineering, E.; States, U. Nanodiamond Nano fluids for Enhanced Thermal Conductivity. ACS Nano 2013, 7, 3183-3189. [CrossRef] [PubMed]

27. Akhgar, A.; Toghraie, D. An experimental study on the stability and thermal conductivity of water-ethylene glycol/TiO ${ }_{2}-$ MWCNTs hybrid nanofluid: Developing a new correlation. Powder Technol. 2018, 338, 806-818. [CrossRef]

28. Yan, S.R.; Kalbasi, R.; Karimipour, A.; Afrand, M. Improving the thermal conductivity of paraffin by incorporating MWCNTs nanoparticles. J. Therm. Anal. Calorim. 2020, 1-8. [CrossRef]

29. Almanassra, I.W.; Manasrah, A.D.; Al-Mubaiyedh, U.A.; Al-Ansari, T.; Malaibari, Z.O.; Atieh, M.A. An experimental study on stability and thermal conductivity of water/CNTs nanofluids using different surfactants: A comparison study. J. Mol. Liq. 2020, 304, 111025. [CrossRef]

30. Choi, S.U.S.; Zhang, Z.G.; Yu, W.; Lockwood, F.E.; Grulke, E.A. Anomalous thermal conductivity enhancement in nanotube suspensions. Appl. Phys. Lett. 2001, 79, 2252. [CrossRef]

31. Hemmat Esfe, M.; Saedodin, S.; Biglari, M.; Rostamian, H. Experimental investigation of thermal conductivity of CNTs$\mathrm{Al}_{2} \mathrm{O}_{3}$ /water: A statistical approach. Int. Commun. Heat Mass Transf. 2015, 69, 29-33. [CrossRef]

32. Farbod, M.; Ahangarpour, A.; Etemad, S.G. Stability and thermal conductivity of water-based carbon nanotube nanofluids. Particuology 2015, 22, 59-65. [CrossRef]

33. Ilyas, S.U.; Pendyala, R.; Narahari, M. Stability and thermal analysis of MWCNT-thermal oil-based nanofluids. Colloids Surf. A Physicochem. Eng. Asp. 2017, 527, 11-22. [CrossRef]

34. Shanbedi, M.; Heris, S.Z.; Amiri, A.; Hosseinipour, E.; Eshghi, H.; Kazi, S.N. Synthesis of aspartic acid-treated multi-walled carbon nanotubes based water coolant and experimental investigation of thermal and hydrodynamic properties in circular tube. Energy Convers. Manag. 2015, 105, 1366-1376. [CrossRef]

35. Selvam, C.; Lal, D.M.; Harish, S. Thermal conductivity enhancement of ethylene glycol and water with graphene nanoplatelets. Thermochim. Acta 2016, 642, 32-38. [CrossRef]

36. Yu, W.; Xie, H.; Li, Y.; Chen, L.; Wang, Q. Experimental investigation on the thermal transport properties of ethylene glycol based nanofluids containing low volume concentration diamond nanoparticles. Colloids Surf. A Physicochem. Eng. Asp. 2011, 380, 1-5. [CrossRef]

37. Peña-Parás, L.; Maldonado-Cortés, D.; Taha-Tijerina, J. Eco-Friendly Nanoparticle Additives for Lubricants and Their Tribological Characterization. In Handbook of Ecomaterials, 1st ed.; Torres-Martínez, L.M., Kharissova, O.V., Kharisov, B.I., Eds.; Springer International Publishing: Cham, Switzerland, 2018; pp. 1-21.

38. Peña-Parás, L.; Maldonado-Cortés, D.; Kharissova, O.V.; Saldívar, K.I.; Contreras, L.; Arquieta, P.; Castaños, B. Novel carbon nanotori additives for lubricants with superior anti-wear and extreme pressure properties. Tribol. Int. 2019, 131, 488-495. [CrossRef]

39. Kharissova, O.V.; Garza Castañón, M.; Kharisov, B.I. Inorganic nanorings and nanotori: State of the art. J. Mater. Res. 2019, 34, 3998-4010. [CrossRef] 
40. Wang, N.; Xu, G.; Li, S.; Zhang, X. Thermal Properties and Solar Collection Characteristics of Oil-based Nanofluids with Low Graphene Concentration. Energy Procedia 2017, 105, 194-199. [CrossRef]

41. Hamid, K.A.; Azmi, W.H.; Nabil, M.F.; Mamat, R.; Sharma, K.V. Experimental investigation of thermal conductivity and dynamic viscosity on nanoparticle mixture ratios of $\mathrm{TiO}_{2}-\mathrm{SiO}_{2}$ nanofluids. Int. J. Heat Mass Transf. 2018, 116, 1143-1152. [CrossRef]

42. Kurt, H.; Kayfeci, M. Prediction of thermal conductivity of ethylene glycol-water solutions by using artificial neural networks. Appl. Energy 2009, 86, 2244-2248. [CrossRef]

43. Challoner, A.R.; Powell, R.W. Thermal Conductivities of Liquids: New Determinations for Seven Liquids and Appraisal of Existing Values. Proc. R. Soc. A Math. Phys. Eng. Sci. 1956, 238, 90-106.

44. Glory, J.; Bonetti, M.; Helezen, M.; Mayne-L'Hermite, M.; Reynaud, C. Thermal and electrical conductivities of water-based nanofluids prepared with long multiwalled carbon nanotubes. J. Appl. Phys. 2008, 103, 094309. [CrossRef]

45. Czarnetzki, W.; Roetzel, W. Temperature oscillation techniques for simultaneous measurement of thermal diffusivity and conductivity. Int. J. Thermophys. 1995, 16, 413-422. [CrossRef]

46. Rodríguez-Laguna, M.R.; Castro-Alvarez, A.; Sledzinska, M.; Maire, J.; Costanzo, F.; Ensing, B.; Pruneda, M.; Ordejón, P.; Sotomayor Torres, C.M.; Gómez-Romero, P.; et al. Mechanisms behind the enhancement of thermal properties of graphene nanofluids. Nanoscale 2018, 10, 15402-15409. [CrossRef]

47. Rodriguez-Laguna, M.R.; Torres, C.M.S.; Gomez-Romero, P.; Chavez-Angel, E. On the Enhancement of the Thermal Conductivity of Graphene-Based Nanofluids. In Proceedings of the IEEE 18th International Conference on Nanotechnology, Cork, Ireland, 23-26 July 2018; p. 8626244.

48. Rudyak, V.Y.; Minakov, A.V.; Pryazhnikov, M.I. Preparation, characterization, and viscosity studding the single-walled carbon nanotube nanofluids. J. Mol. Liq. 2021, 329, 115517. [CrossRef]

49. Tahmooressi, H.; Daviran, S.; Kasaeian, A.; Rashidi, A. Percolating micro-structures as a key-role of heat conduction mechanism in nanofluids. Appl. Therm. Eng. 2017, 114, 346-359. [CrossRef]

50. Du, B.; Jian, Q. Size controllable synthesis of graphene water nanofluid with enhanced stability. Fuller. Nanotub. Carbon Nanostruct. 2019, 27, 87-96. [CrossRef]

51. Barai, D.P.; Bhanvase, B.A.; Sonawane, S.H. A Review on Graphene Derivatives-Based Nanofluids: Investigation on Properties and Heat Transfer Characteristics. Ind. Eng. Chem. Res. 2020, 59, 10231-10277. [CrossRef]

52. Taha-Tijerina, J.; Ribeiro, H.; Aviña, K.; Martínez, J.M.; Godoy, A.P.; Cremonezzi, J.M.d.O.; Luciano, M.A.; Gimenes Benega, M.A.; Andrade, R.J.E.; Fechine, G.J.M.; et al. Thermal Conductivity Performance of 2D h-BN/MoS $2 /$-Hybrid Nanostructures Used on Natural and Synthetic Esters. Nanomaterials 2020, 10, 1160. [CrossRef]

53. Singh, A. Thermal Conductivity of Nanofluids. Def. Sci. J. 2008, 58, 600-607. [CrossRef]

54. Dey, D.; Sahu, D.S. A review on the application of the nanofluids. Heat Transf. 2021, 50, 1113-1155. [CrossRef]

55. Shukla, K.N.; Koller, T.M.; Rausch, M.H.; Fröba, A.P. Effective thermal conductivity of nanofluids-A new model taking into consideration Brownian motion. Int. J. Heat Mass Transf. 2016, 99, 532-540. [CrossRef]

56. Yazid, M.N.A.W.M.; Sidik, N.A.C.; Yahya, W.J. Heat and mass transfer characteristics of carbon nanotube nanofluids: A review. Renew. Sustain. Energy Rev. 2017, 80, 914-941. [CrossRef]

57. Ribeiro, H.; Trigueiro, J.P.C.; Silva, W.M.; Woellner, C.F.; Owuor, P.S.; Cristian Chipara, A.; Lopes, M.C.; Tiwary, C.S.; Pedrotti, J.J.; Villegas Salvatierra, R.; et al. Hybrid MoS2/h-BN Nanofillers As Synergic Heat Dissipation and Reinforcement Additives in Epoxy Nanocomposites. ACS Appl. Mater. Interfaces 2019, 11, 24485-24492. [CrossRef]

58. Taha-Tijerina, J.; Peña-Parás, L.; Maldonado-Cortés, D. Cortés, D. Cortés 2D-Based Nanofluids: Materials Evaluation and Performance. In Two-Dimensional Materials-Synthesis, Characterization and Potential Applications; Nayak, P.K., Ed.; InTech: Rijeka, Croatia, 2016; pp. 153-198, ISBN 978-953-51-2554-9.

59. Taha-Tijerina, J.; Cadena-de la Peña, N.; Cue-Sampedro, R.; Rivera-Solorio, C. Thermo-physical evaluation of dielectric mineral oil-based nitride and oxide nanofluids for thermal transport applications. J. Therm. Sci. Technol. 2019, 14, JTST0007. [CrossRef]

60. Iqbal, S.M.; Raj, C.S.; Michael, J.J.; Irfan, A.M. A Comparative Investigation of $\mathrm{Al}_{2} \mathrm{O}_{3} / \mathrm{H}_{2} \mathrm{O}, \mathrm{SiO}_{2} / \mathrm{H}_{2} \mathrm{O}$ and $\mathrm{ZrO}_{2} / \mathrm{H}_{2} \mathrm{O}$ Nanofluid for Heat Transfer Applications. Dig. J. Nanomater. Biostruct. 2017, 12, 255-264.

61. Shima, P.D.; Philip, J.; Raj, B. Synthesis of Aqueous and Nonaqueous Iron Oxide Nanofluids and Study of Temperature Dependence on Thermal Conductivity and Viscosity. J. Phys. Chem. C 2010, 114, 18825-18833. [CrossRef]

62. Baby, T.T.; Sundara, R. Synthesis and Transport Properties of Metal Oxide Decorated Graphene Dispersed Nanofluids. J. Phys. Chem. C 2011, 115, 8527-8533. [CrossRef]

63. Kleinstreuer, C.; Feng, Y. Experimental and theoretical studies of nanofluid thermal conductivity enhancement: A review. Nanoscale Res. Lett. 2011, 6, 229. [CrossRef] [PubMed]

64. Hashin, Z.; Shtrikman, S. A Variational Approach to the Theory of the Effective Magnetic Permeability of Multiphase Materials. J. Appl. Phys. 1962, 33, 3125. [CrossRef]

65. Marquis, F.D.S.; Chibante, L.P.F. Improving the heat transfer of nanofluids and nanolubricants with carbon nanotubes. JOM 2005, 57, 32-43. [CrossRef]

66. Kim, P.; Shi, L.; Majumdar, A.; McEuen, P.L. Thermal Transport Measurements of Individual Multiwalled Nanotubes. Phys. Rev. Lett. 2001, 87, 215502. [CrossRef] [PubMed]

67. Berber, S.; Kwon, Y.-K.; Tománek, D. Unusually High Thermal Conductivity of Carbon Nanotubes. Phys. Rev. Lett. 2000, 84, 4613-4616. [CrossRef] [PubMed] 
68. Hone, J.; Whitney, M.; Zettl, A. Thermal conductivity of single-walled carbon nanotubes. Synth. Met. 1999, 103, 2498-2499. [CrossRef]

69. Kang, H.U.; Kim, S.H.; Oh, J.M. Estimation of Thermal Conductivity of Nanofluid Using Experimental Effective Particle Volume. Exp. Heat Transf. 2006, 19, 181-191. [CrossRef] 